\title{
Audit of patients with chest pain presenting to an accident and emergency department over a 6-month period
}

\author{
N. J. FOTHERGILL, M. T. HUNT \& R. TOUQUET \\ Accident and Emergency Department, St Mary's Hospital, Praed Street, London \\ W2 1NY
}

\section{SUMMARY}

The results of a 6-month retrospective audit of patients presenting with chest pain to an accident and emergency (A\&E) department to which 46000 new patients per year present are discussed. The computer diagnostic code assigned to the patients by the A\&E doctor, referral rates for second opinion and disposal after assessment in the A\&E department are examined, with particular reference to patients who may have had serious cardiac pathology, such as acute myocardial infarction (AMI) or unstable angina.

Audit showed that overall $61 \%$ of patients with chest pain of all causes were assessed and discharged home by A\&E doctors without recourse to second opinion. Of patients thought by the A\&E doctors to have chest pain of cardiac origin, who were referred to the duty medical registrar or cardiologist, $88 \%$ were admitted. As a result of these findings a policy of more open referral for second opinion was instituted to reduce the likelihood of discharging patients home with serious cardiac pathology. In addition, the clinical problems of AMI and unstable angina are emphasized to all senior house officers early in their educational programme after joining A\&E.

Published literature on the diagnosis and misdiagnosis of AMI and unstable angina in the A\&E department is reviewed. These studies are almost exclusively from North America, and a need for similar work in the U.K. is discussed.

\section{INTRODUCTION}

Chest pain is a sympton with which many patients present to the A\&E department. A\&E doctors must 'weed out' those patients who may have AMI or unstable

Correspondence: $\operatorname{Dr}$ N. J. Fothergill, Accident and Emergency Department, St Mary's Hospital, Praed Street, Paddington, London W2 1NY. 
angina, and refer them for treatment and hospital admission. The consequences of not diagnosing, but discharging home, patients with significant cardiac pathology, may be serious. Not only may the patient be denied life-saving treatment for cardiac arrhythmias, but also the chance of benefiting from thrombolytic and antiplatelet therapy, which is now of proven value in reducing mortality from AMI (AIMS Trial Study Group, 1988; ISIS - 2 Collaborative Group 1988).

Although studies from North America and Israel have followed up patients admitted and discharged from A\&E departments with chest pain, there is no work which assesses British doctors' ability to identify patients with AMI or unstable angina (Schor $e t$ al., 1976; Lee et al., 1987). As a preliminary to a long-term followup, this 6-month retrospective audit of computerized A\&E records was undertaken to determine the A\&E doctors diagnoses, and the disposal of patients who presented to the A\&E department with chest pain.

\section{METHODS}

The A\&E records of St Mary's Hospital have been computerized since September 1987, using the Footman Walker-Unisys System (Grout et al., 1989).

Nursing staff provide the Receptionists with a free text 'presenting complaint' after assessing the patient, either at the Triage Desk, or in the major or resuscitation areas of the A\&E department. All those whose presenting complaint was 'chesE pain' were included in the study.

The A\&E doctor enters remaining details immediately after assessing the patient ${ }^{\circ}$ and when the patient leaves the department. A diagnostic code is selected and a free text diagnosis entered. For this study, patients have been categorized into four groups; those coded as having chest pain of 'cardiac', 'respiratory' or 'gastrointestinal' origin; and those given other codes such as 'contusion' or 'non-specific' being referred to as 'others'. Referral for second opinion and disposal of the patient from the A\&E department is entered into the computer by the A\&E doctor when the patient leaves the department, and this information has also been assessed.

For the audit, records of all patients presenting with chest pain from 1 October 1987 to 31 March 1988 were assessed.

\section{RESULTS}

During the study period, 24321 new patients were seen in the departments, of whom $589(2.4 \%)$ presented with chest pain. The age range of the patients is shown in Table 1.

Within each age group there was little difference between the sexes in the proportion of patients given each diagnostic code by the A\&E doctor. Those coded as cardiac rose progressively from $6 \%$ in the $16-24$ age range, to $66 \%$ in those over 65 years. Those not coded as having cardiac, respiratory or gastrointestinal 
Table 1. Diagnostic codes selected by A\&E doctors on discharge of patients who presented with chest pain to the A\&E department

Diagnostic codes

\begin{tabular}{|c|c|c|c|c|c|c|c|c|}
\hline \multirow{2}{*}{$\begin{array}{l}\text { Age } \\
\text { Range } \\
\text { years }\end{array}$} & \multicolumn{2}{|c|}{ Cardiac } & \multicolumn{2}{|c|}{ Respiratory } & \multicolumn{2}{|c|}{$\begin{array}{c}\text { Gastro- } \\
\text { intestinal }\end{array}$} & \multicolumn{2}{|c|}{ 'Others' } \\
\hline & $\mathbf{M}$ & $\mathrm{F}$ & $\mathbf{M}$ & $\mathrm{F}$ & M & F & $\mathbf{M}$ & $\mathrm{F}$ \\
\hline 15 \& under & 0 & 0 & 2 & 1 & 0 & 0 & 0 & 0 \\
\hline $16-25$ & 2 & 1 & 7 & 6 & 7 & 0 & 16 & 11 \\
\hline $26-35$ & 18 & 4 & 8 & 5 & 9 & 0 & 36 & 9 \\
\hline $36-45$ & 21 & 7 & 7 & 4 & 10 & 1 & 38 & 9 \\
\hline $46-55$ & 41 & 11 & 7 & 6 & 9 & 5 & 22 & 2 \\
\hline $56-65$ & 36 & 8 & 14 & 2 & 5 & 3 & 15 & 4 \\
\hline $66-75$ & 31 & 12 & 7 & 4 & 4 & 4 & 13 & 3 \\
\hline $76-85$ & 14 & 14 & 5 & 1 & 2 & 1 & 4 & 5 \\
\hline 86 \& over & 13 & 8 & 1 & 2 & 3 & 2 & 5 & 2 \\
\hline \multirow[t]{2}{*}{ Total } & 176 & 65 & 58 & 31 & 49 & 16 & 149 & 45 \\
\hline & \multicolumn{2}{|c|}{$241(41 \%)$} & \multicolumn{2}{|c|}{$89(15 \%)$} & \multicolumn{2}{|c|}{$65(11 \%)$} & \multicolumn{2}{|c|}{$194(33 \%)$} \\
\hline
\end{tabular}

pain are referred to as 'others'; in younger patients, $50 \%$ of those in this category were coded as having 'non specific' chest pain: the proportion of patients with this coding fell progressively with increasing age.

Overall, $61 \%$ (362) of all patients with chest pain were assessed and discharged by the A\&E doctors, and $39 \%$ (227) were referred for a second opinion of whom $79 \%$ (179) were admitted.

Of all patients in the study, $41 \%$ (241) had pain which was coded by the A\&E doctor as cardiac. A total of $33 \%$ of these patients ( 80 patients) were discharged home by the A\&E doctors, $74 \%$ without arrangement for follow up by their GP or in hospital clinics. A total of 161 were referred for specialist opinion, of whom 141 $(88 \%)$ were admitted (Table 2). These 161 patients made up almost three-quarters of those patients with chest pain referred for second opinion.

Table 2. Percentage of patients with chest pain coded by A\&E doctors as cardiac and referred for second opinion who were admitted

\begin{tabular}{|c|c|c|c|c|c|c|}
\hline \multirow[b]{2}{*}{ Age } & \multicolumn{3}{|c|}{ Men } & \multicolumn{3}{|c|}{ Women } \\
\hline & Referred & Admitted & $\%$ & Referred & Admitted & $\%$ \\
\hline $16-25$ & 2 & 1 & 50 & 0 & 0 & - \\
\hline $26-35$ & 7 & 4 & 57 & 0 & 0 & - \\
\hline $36-45$ & 13 & 9 & 69 & 3 & 3 & 100 \\
\hline $46-55$ & 29 & 27 & 93 & 6 & 6 & 100 \\
\hline $56-65$ & 26 & 20 & 77 & 3 & 3 & 100 \\
\hline $66-75$ & 22 & 21 & 95 & 11 & 9 & 82 \\
\hline $76-85$ & 11 & 11 & 100 & 12 & 11 & 92 \\
\hline $86-95$ & 9 & 9 & 100 & 7 & 7 & 100 \\
\hline Total & 119 & 102 & 86 & 42 & 39 & 93 \\
\hline
\end{tabular}


Overall, 91\% of those in the 'others' category were discharged by A\&E doctor (175 of 193 patients) without recourse to specialist opinion.

\section{DISCUSSION}

In 1988 there were over 175000 registered deaths from ischaemic heart disease in the U.K. (HMSO, 1989). A recent study showed that $80 \%$ of patients admitted tow the coronary care unit (CCU) of a district general hospital with subsequentlyo proven AMI presented directly to the A\&E department, the remainder being $\vec{\omega}$ referred to hospital by their GP (Dalton et al., 1989).

From the 1960 's to the 1980 's, mortality of CCU patients has fallen from 35 to $15 \%$, mainly due to improved pharmacological and electrical therapy for lifethreatening arrhythmias. With thrombolytic therapy now widely available, and of proven value in reducing both immediate and 1 year mortality from AMI, (APSAC by over $50 \%$, AIMS Trial Study Group 1988), it is doubly tragic if a patient who is infarcting is not diagnosed correctly, and is discharged from the A\&E department.?

A study from Nottingham reassuringly demonstrated a good prognosis fors patients discharged after CCU admission with a diagnosis of 'chest pain? cause', $\frac{\mathbb{O}}{0}$ but what of those who are discharged from the A\&E department? (Wilcox et al., $\stackrel{\mathbb{1}}{3}$ 1981). Studies from Israel and North America have shown that between 5 and \&o요 of patients with AMI are discharged mistakenly from the A\&E department, a\&d that there is excess mortality in these patients who are significantly younger, ande\% present with less typical symptoms than those admitted (Schor et al., 1976; Lege et al., 1987). No such data are available from the U.K.

The diagnosis of AMI and unstable angina is clinical, based largely upon theo physician's interpretation of the history obtained from the patient; examination iso usually normal, and initial ECG changes may be absent or subtle.

The differential diagnosis of patients who experience chest pain which is indis-⿳⺈⿴囗十⺝⿱⺈ tinguishable on history from classical angina pectoris, and the similarity between cardiac and oesophageal pain, have received much attention in prospective studieso (Davies et al., 1982), review articles (Magarian et al., 1986) and editorial commento (Anon, 1982; Bennett, 1983; Anon, 1986). It is worrying that $11 \%$ of all patients in this study had chest pain coded as gastrointestinal after clinical assessment by an $A \& E$ doctor, having had at most a chest $X$-ray and ECG by way of investigation. From the A\&E doctor's point of view, the differential diagnosis of those with chest pain which is not similar to classical angina pectoris, is also of great importance.? It is not known whether any of those coded as having 'non-specific chest pain' in this study had serious cardiac pathology, however, nine out of ten were discharged home by the A\&E doctors without recourse to second opinion.

In the U.S.A., Goldman et al. (1982) and Tierney et al. (1985) have attemptedn to characterize the presentation and outcome of patients attending A\&E depart ments with chest pain, and derive clinical algorhythms for the use of emergencye physicians.

From these studies it is apparent that whilst over half those who give a description of classical angina pectoris lasting for between 10 and 120 min have AMI or unstable 
angina, many patients experience different types of pain. Of those with 'sharp or stabbing' pain, $22 \%$ had AMI or unstable angina, and $19 \%$ of those with AMI had sharp or pleuritic discomfort. Examination is unremarkable in the majority of cases, and abnormal findings may be misleading, such as chest wall tenderness which was found at presentation in $15 \%$ of those later found to have AMI. The initial ECG is diagnostic in only $25-50 \%$ of those subsequently shown to have infarcted, and is normal or shows non-specific ST-T changes in $10 \%$ (McGuiness et al., 1976). Those with 'low-risk' initial ECG's have a lower mortality than those with 'high-risk' initial tracings (Rouan et al., 1987).

Detailed review of the literature on the evaluation of patients with chest pain in the A\&E department leaves one without clear guidelines as to who to admit or who to send home (Hedges et al., 1989).

In Britain the initial screening of the majority of patients who may later be shown to have had AMI is carried out by A\&E doctors who may not be experienced in the assessment of chest pain, by virtue of being recently qualified. This study showed that almost two-thirds of patients presenting with chest pain of all causes were assessed by the A\&E doctor alone before being discharged home. The more experienced admitting physician may fail to admit some patients who were correctly referred to them.

In the study four out of five patients with chest pain referred for second opinion were admitted to hospital. In the U.K. there are no data to show the sensitivity or specificity of diagnosis of AMI or unstable angina, and no way, therefore, of judging a unit's or hospital's performance.

In the U.S.A. although only $2 \%$ of adult emergency department visits are for assessment of chest discomfort, $20 \%$ of total expenditure by the American College of Emergency Physicians affiliated malpractice insurance programme is related to the diagnosis and treatment of myocardial infarction alone (Dunn, 1986). Without this stimulus in the U.K., it is reasonable to suppose that we are less cautious in the assessment of patients with chest pain, possibly discharging more than $5 \%$ of patients with AMI from A\&E departments. American cardiologists aim to have a $5-10 \%$ infarction rate in their CCU admissions, with $90-95 \%$ of patients later proving not to have had an acute infarct. A separate cost effective analysis supported this infarction admission rate in the U.S.A. in 1984 (Fineberg et al., 1984).

Further, more detailed audit of those admitted and discharged from A\&E departments in Britain after assessment of chest pain is urgently required.

\section{REFERENCES}

AIMS Trial Study Group (1988) Effect of intravenous APSAC on mortality after acute myocardial infarction: Preliminary report of a placebo controlled clinical trial. Lancet 8585(1), 545-549.

Anon (1982) Editorial - Chest pain: heart? gullet? both? neither? Journal of the American Medical Association 248(18), 1315.

Anon (1986) Editorial - Angina and oesophageal disease. Lancet 8474(1), 191-192.

Bennett J. R. (1983) Chest pain: heart or gullet? British Medical Journal 286, 1231-1232.

Dalton H., Chappel D. \& Climie R. (1989) Thrombolysis for acute myocardial infarction in a District General Hospital. Journal of the Royal Society of Medicine 82(7), 394-5. 
Davies H. A., Jones D. B. \& Rhodes J. (1982) 'Esophageal Angina' as the cause of chest pain. Journal the American Medical Association 248(18), 2274-2278

Dunn J. (1986) ACEP Foresight: Chest Pain, pp. 1-3. ACEP publications, Dallas.

Fineberg H. V., Scadden D. \& Goldman L. (1984) Care of patients with a low probability of acute. myocardial infarction: Cost effectiveness of alternatives to Coronary Care Unit admission. Necte England Journal of Medicine 310, 1301-1307.

Goldman L., Weinberg M. \& Weisberg M. et al. (1982) A computer derived protocol to aid in the diagnosis of Emergency Room patients with acute chest pain. Nerw England Journal of Medicine 30\% 588-596.

Grout P., Hunt M. T. \& Touquet R. (1989) The benefits of an accident \& emergency computer systeme् Theoretical Surgery 4, 1-9.

Hedges J. R. \& Kobernick M. S. (1989) Detection of myocardial ischaemia or infarction in the Emergency Department patient with chest discomfort Entergency Medicine Clinics of North Amterica 6(2), 317-340-

HMSO (1989) Population Trends, Summer 1989. HMSO 8730011. HMSO, London

ISIS-2 Collaborative Group (1988) Randomised trial of intravenous streptokinase, oral aspirin, both of neither among 17, 187 cases of acute myocardial infarction. Lancet ii, 349-360.

Lee T. H., Gregory W., Rouan W. et al. (1987) Clinical characteristics and natural history of patient $\vec{P}$ with acute myocardial infarction sent home from the emergency room. American Journal of Cardiologi 60, 219-224.

Magarian G. J. \& Hickham D. H. (1986) Non cardiac causes of angina-like chest pain. Progress $i$ Cardiovascular Diseases 29(1), 65-80.

McGuiness J. B., Begg T. B. \& Semple T. (1976) First electrocardiogram in recent myocardial infarction $\overrightarrow{f s}$ British Medical Journal 2, 449-451.

Rouan G. W., Lee T. H., Cook E. F. et al. (1987) Clinical characteristics of patients with acute myocardia infarctions and non specific electrocardiograms. Clinical Research 35, 360A.

Schor S., Benar S., Modan B. et al. (1976) Disposition of presumed coronary patients from an Emergerc⿻ Room. A follow up study. Journal of the American Miedical Association 236, 941-943.

Tierney W. M., Roth B. J., Psaty B. et al. (1985) Predictors of myocardial infarction in emergency reme patients. Critical Care Medicine 13, 526-531.

Wilcox R. G., Roland J. M. \& Hampton J. R. (1981) Prognosis of patients with "chest pain? caușe' British Medical Journal 282, 431-433. 